\title{
Behavior of diabetic retinopathy in patients attending the diabetic center of Colón 2017
}

\begin{abstract}
Summary
The impact of Diabetes Mellitus on the world population has caused it to be considered as a health problem. For years Diabetic retinopathy (RD) has been the main cause of disability and blindness among professionally active adults in economically developed societies. A cross-sectional descriptive study was carried out in order to determine the prevalence of diabetic retinopathy in diabetic patients treated at the Diabetic Care Center in the Municipality of Colón, Matanzas Province from January to December 2017. The universe was comprised of 200 diabetic patients received diurnal income; the sample was made up of 67 diabetics with retinopathy, the study variables were obtained by collecting information from the medical records. The results obtained were: the age that predominated was over 60 years, the female sex was the one that affected, the risk factor that influenced was arterial hypertension, the admissible metabolic control, the time of evolution of the diabetes that prevailed was of 6 to 10 years, and type 2 diabetes was the most influential. Non-proliferative diabetic retinopathy prevailed. It is concluded that the non-proliferative diabetic retinopathy was the most diagnosed, the majority of the patients had a bad visual acuity. The results show that the continuous ocular evaluation of the diabetic patients is necessary.
\end{abstract}

Keywords: diabetes mellitus, diabetic retinopathy, health problem, macro vascular, chronic microangiopathic, diabetic patient, age, sex, degree of control, metabolic, time of evolution, types of diabetes, associated diseases
Volume 2 Issue 6 - 2018

\author{
Esther Catalá Sardiñas, ' Ana Berkis Montalvo \\ Herrera, ${ }^{2}$ Imayasil Gónzalez Lozada ${ }^{3}$ \\ 'Bachelor of Nursing, Master of Science, Nurse of the Diabetic \\ Care Center, Full Member of the SOCUENF, Assistant Professor. \\ Aggregate Investigator, Cuba \\ ${ }^{2}$ Bachelor of Nursing, Master of Science, Assistant Professor, Full \\ Member of SOCUENF, Cuba \\ ${ }^{3}$ Specialist in General Ophthalmology at the Hospital Mario \\ Muñoz Monrroy de Colón, Instructor Professor, Cuba
}

\author{
Correspondence: Esther Catalá Sardiñas, Bachelor of Nursing, \\ Master of Science, Nurse of the Diabetic Care Center, Full \\ Member of the SOCUENF, Assistant Professor, Aggregate \\ Investigator, Cuba, Tel 45 3I-35II, \\ Email esthercatala.mtz@infomed.sld.cu
}

Received: July 0I, 2018 | Published: December 20, 2018

\section{Introduction}

Diabetes mellitus (DM) is an alteration of insulin secretion and variable degrees of peripheral resistance to insulin that cause hyperglycemia. After years of poorly controlled hyperglycemia, there are multiple complications, mainly vascular, that affect the small (microvascular) and large (macro vascular) blood vessels. The micro vascular are the basis of the three most devastating manifestations of (DM): retinopathy, nephropathy and neuropathy. Diabetic retinopathy is the most common cause of blindness in adults in the USA. ${ }^{1}$ In 1995, adult diabetics in the world were approximately 135 million, it is estimated that by 2025 this figure will be 300 million, an increase that will be at the expense of the Developing countries. It is estimated that there are currently 93 million people with diabetic retinopathy (RD), of them 21 million with macular edema and 28 million with threat of vision loss by (RD). Diabetic retinopathy (RD), is detected in $25 \%$ of diabetics, a percentage that can reach $44 \%$ in those who have more of 15 years of evolution of the disease. ${ }^{2}$ It is known exactly that sustained hyperglycemia is the main cause of microcirculatory disorders in the (DM). Within these, the (RD) plays a significant role and together with diabetic neuropathy, it is the most common microangiopathies in diabetes mellitus. ${ }^{3}$ The (RD) is an eye disease caused by the chronic microangiopathic complications of diabetes mellitus (DM), and is the main cause of blindness in patients suffering from the disease. Approximately $78 \%$ of type II diabetics have some degree of (RD) in the 15 years after diagnosis of the disease. ${ }^{3}$

The constant increase in life expectancy in the diabetic patient, as well as the incidence of diabetic disease itself, inevitably leads to an increase in the magnitude of the problem represented by diabetic retinopathy (RD). For years, the (RD) is the fundamental cause of disability and blindness among adults active professionally in economically developed societies. The (RD) is fundamentally similar in DM type 1 and type 2 and it is widely accepted that its early diagnosis and treatment prevents the loss of vision by (RD). ${ }^{4}$ Diabetic retinopathy $(\mathrm{RD})$ is associated with the presence of risk factors that determine both its emergence and the increase in its severity. Among these are: duration and type of DM, poor metabolic control, pregnancy, history of hypertension, kidney disease, obesity, hyperlipidemia, smoking and genetic factors. Age, sex and race could not be demonstrated conclusively as risk factors. ${ }^{5}$ The retinal microangiopathy is the cause of one of the most severe diabetic manifestations from the functional point of view. The (RD) is a progressive microangiopathy characterized by lesions and occlusions of the retinal vessels in people with diabetes mellitus (DM). The visual deterioration has a negative impact on the quality of life of the diabetic patient in a very variable proportion according to the coexistence or not of other factors. The effectiveness of the control of the disease and the visual functional repercussion of it, form the basis of an inter-related binomial as a vicious circle, which usually leads to a spontaneous tendency to deterioration. ${ }^{6}$

Speaking of early treatment inevitably involves the consideration of the classical systems on which any action in the field of preventive medicine is based. In this regard, it is essential to have the most exhaustive knowledge possible of the population on which we intend to act to prepare any intervention plan, as well as to evaluate the use and distribution of existing resources of whatever kind. The estimation of the overall prevalence of retinopathy in a diabetic population depends on the criteria used for its diagnosis and the age of the population studied. Multiple studies report figures between 20 and $50 \%{ }^{7}$ In Cuba, no investigations have been carried out at the National level to determine the prevalence of DR. By taking into 
account the importance given to the early search for conditions that potentially lead to blindness and given the increase in its prevalence, the threatening nature of has for the vision and the socioeconomic repercussion that supposes, diabetic retinopathy (RD) has become the central theme of ophthalmology and in a very important problem for public health we are interested in carrying out the following investigation, with the objective of To determine the prevalence of diabetic retinopathy in diabetic patients who attend the Diabetic Care Center of Colón Provincia Matanzas.

\section{Methods}

A cross-sectional descriptive study was carried out with the objective of determining the prevalence of diabetic retinopathy in diabetic patients attending the Center for Diabetic Care of Colón Provincia Matanzas from January to December 2017. Universe: It was constituted by 200 patients who received daytime admission at the Diabetic Care Center. Sample: It consists of 67 diabetic patients who attended the ophthalmology consultation who were diagnosed with retinopathy in the Diabetic Care Center. The criteria designed for the sample were the following:

\section{Inclusion criteria}

Diabetic patients who attended the ophthalmology consultation at the Diabetic Care Center and willing to participate in the research.

\section{Exclusion criteria}

Patients who did not attend the ophthalmology consultation, patients with DM gestacionar or secondary to another disease and patients who did not agree to participate in the investigation.

\section{Instruments}

The clinical history was carried out, which has all the necessary parameters for the study. In addition, they underwent glycemia to know the metabolic control they had before carrying out the research, previously informed consent was taken. The data was entered into a database and processed in a Pentium 4 Microsoft Excel version 6.0. The results were expressed in percentages that allowed the understanding and correlation of the variables arriving at conclusions.

\section{The study variables were}

Age, Sex, Degree of control, metabolic, Time of evolution, Types of Diabetes, Associated Diseases, Type of Retinopathy.

\section{Procedure}

A clinical history was compiled for the included patients, which includes all the previously structured information. The examination and ophthalmological examination included: taking the best corrected visual acuity, intraocular pressure, biomicroscopy of the anterior/ posterior segment and direct ophthalmoscopy after dilatation. The patients diagnosed with diabetic retinopathy were referred to the ophthalmology service of the Dr. Mario Muños Monrroy Hospital in Colón to be examined and perform indirect ophthalmoscopy, background photography, fluorescein angiography and optical coherence tomography. Ethical Aspects: Recruitment will be done through informed consent Table 1, participation will be totally voluntary and non-participation will not affect your care by the Diabetic Care Center. The confidentiality of the data obtained will be guaranteed. The staff that will carry out the investigation has the necessary preparation to carry it out. In the case of detecting alterations in the physical examination and/or the complementary ones, which suggest any type of illness, the corresponding medical attention will be guaranteed.

Table I General characteristics of the sample studied

\begin{tabular}{llll}
\hline Variables & & $\mathbf{n}$ & $\mathbf{( \% )}$ \\
\hline Sex & Female & 40 & 59,7 \\
& Male & 27 & 40,2 \\
Age group & $23-32$ & 3 & 4,4 \\
& $33-4 \mid$ & 5 & 7,4 \\
& $42-50$ & 7 & 10.4 \\
& $51-59$ & 9 & 13,4 \\
Metabolic control & More than 60 & 43 & 64,1 \\
Years of evolution of & Suitable & 23 & 34,3 \\
the disease & Inadequate & 37 & 55,2 \\
& 5-Jan & 7 & 10,4 \\
& I0-Jun & 25 & 37,3 \\
& More than 10 & 28 & 41,7 \\
Ayssociated Diseases & Arterial hypertension & 14 & 20,8 \\
& Glaucoma & 67 & 100 \\
& High Cholesterol figures & 7 & 10,4 \\
& I & 12 & 17,9 \\
& 2 & 54 & 80,5 \\
\hline
\end{tabular}

Source: Clinical histories. DM = Diabetes Mellitus. The percentages were calculated based on the total sample. $(n=67)$

\section{Results}

When analyzing the behavior related to age we see that the highest prevalence was among those over 60 years, which represents $64,1 \%$ of the sample, the prevailing gender was the female with 40 patients represented by $59 \%$, with Regarding the time of evolution of diabetes, we found that the patients studied predominated those who had 6-10 years of evolution of the disease with 28 patients, representing $41.7 \%$ of the sample Table 2. In terms of metabolic control, there was a greater incidence in those patients who were in a permissible range with $55.2 \%$, according to type of diabetes there was a predominance in type 2 diabetes with 54 patients representing $80.5 \%$, diseases associated with high blood pressure prevailed by $100 \%$. Nonproliferative diabetic retinopathy (RDNP) was found in 52 patients of the study sample, representing $77.6 \%$.

Table 2 Distribution of diabetic patients according to type of diabetic retinopathy

\begin{tabular}{lll}
\hline Type of Diabetic Retinopathy & No. of patients & $\%$ \\
\hline Nonproliferative & 52 & 77,6 \\
Proliferative & 15 & 22,3 \\
Total & 67 & 100 \\
\hline
\end{tabular}

Source: Clinical History 


\section{Discussion}

Age-related eye diseases that cause decreased vision and blindness are a current challenge for professionals and health authorities around the world. ${ }^{8}$ Among them we find RD, cataract, glaucoma and macular degeneration related to age. RD depends on the duration of hyperglycemia rather than the age of the patient. The prevalence of RD among people with DM does not increase significantly when stratified by age, rather it is related to the time of evolution of DM. Although age has not been conclusively demonstrated as a risk factor for RD. ${ }^{9}$ It is suggested that the prevalence of $\mathrm{RD}$ increases in the groups of 6074 years, coinciding with our study which was more frequent starting from of 60 years of age. This corresponds to other studies carried out. Those who obtained results similar to ours, it is said that RD increases in direct relation with age, other authors suggest that a risk factor for retinopathy is poor metabolic control and years of evolution of the disease. The results obtained coincide with other studies, who found that in diabetics over 40 years, the highest prevalence for RD was between 61 to 70 years. Sex has also not been shown to be a significant risk factor for RD. In a similar way to that found in the present investigation, Pérez, $\mathrm{M}$ and collaborators report a relatively higher prevalence in women than in men, respectively. ${ }^{10}$ In our study, the female sex is the most affected. In another study, the prevalence was $23 \% .{ }^{10}$ With regard to the time of evolution of diabetes, we found in our research that of the studied patients, those who had 6-10 years of evolution of the disease with 16 patients who represented $43.2 \%$ of the sample predominated.

It is well established that there is a very strong relationship between the clinical duration or time of evolution of diabetes and the DR where, at a longer time of evolution, greater risk and presence of RD. ${ }^{11}$ In addition, it is not only the time of evolution, other factors affect the appearance of RD, such as poor control of blood sugar and hypertension. On the other hand, it is considered that a great threat to the vision of diabetic patients is the DR because it is the most frequent cause of blindness in Cuba and it is detected in $25 \%$ of diabetics, a percentage that can reach $44 \%$ in those that have more than 15 years of evolution of the disease. ${ }^{12}$ With the proper use of ocular health care, the impact of visual loss can be reduced due to problems related to agerelated eye diseases, including diabetes. ${ }^{13}$ Similarly, type 2 diabetic patients were those that prevailed in the sample studied, in this study $80.5 \%$ of the total population had type $2 \mathrm{DM}$, because they are much more numerous in the general population. The factors that influence the progression of DR and, consequently, the effect it has on retinal complications that lead to irreversible visual loss are well established. Among the general diseases associated with $\mathrm{RD}$, it has been reported that arterial hypertension predominates. According to the study carried out in Madrid (Spain) at the Biomedical Foundation of San Carlos III, good control of blood glucose could reduce the risk of RD by $50 \%$, in the research most patients had a permissible metabolic control. ${ }^{14}$ Diabetic retinopathy is one of the causes of blindness in the world. And the main cause of blindness in people from 25 to 74 years of age. There are about 14 million diabetics in the world but only half of them know they have this disease.

The diabetic population must strictly control their blood glucose, blood pressure and plasma lipids. There are other factors that negatively influence diabetic retinopathy such as obesity, smoking or sedentary lifestyle. These patients (amounting to more than 200 million worldwide) require periodic retinal examinations because, generally, diabetic retinopathy does not cause symptoms until the injury is severe. ${ }^{15}$ It has been verified and ratified that among type 2 Diabetic patients, there is hypertension, dyslipidemia, ischemia cardiopathy, having a very high prevalence among the population of diabetics, in various epidemiological studies it has been proven that approximately between $40 \%$ and $60 \%$ of diabetics suffer from hypertension. ${ }^{16}$ It was shown here that the greatest number of patients suffered from hypertension. The early detection of these diseases guarantees a better quality of life for these patients, the results expressed here show once more the importance of the correct education of diabetic patients in terms of disease control and other associated entities The second is that hypertension is a determining factor in the development and progression of diabetic nephropathy, and it has also been shown that an adequate treatment of hypertension can slow down the progression of this nephropathy and another because hypertension is one of the most important risk factors for hypertension. Development of cardiovascular and cerebrovascular complications, especially in type 2 diabetics. ${ }^{17}$ Retinal involvement is evident in patients with poor control of their diabetes while optimal glycemic control reduces the risk of retinopathy, hence the recommendation to perform annual evaluations with dilated retinal examination, because some diabetic patients may not report symptoms and progress from a mild nonproliferative abnormality to severe proliferative retinopathy ${ }^{18,19}$ The incidence of R.D. Nonproliferative is around $8 \%$ and RD proliferative is around $1 \%$, in our research it was shown that $77.6 \%$ corresponds to patients with non-proliferative diabetic retinopathy. It is known that the ophthalmological manifestations of patients suffering from DM are they become more evident the longer the evolution time of the disease and especially the clinical signs of retinopathy. ${ }^{20}$ It is concluded that: The majority of the patients had a bad visual acuity. The results show that the continuous ocular evaluation of diabetic patients is necessary.

\section{Recommendations}

Perform a complete ophthalmological physical examination in patients with type 1 and 2 diabetes mellitus with the periodicity dictated by the treatment guidelines for these cases. Carry out strategies for the investigation and diagnosis of diabetic retinopathy in diabetic elderly adults. Carry out glycemia studies in the population, for the early diagnosis of diabetes mellitus and thus avoid or delay its complications.

\section{Acknowledgments}

None.

\section{Conflicts of interest}

The author declares there is no conflict of interest.

\section{References}

1. Goldaracena MB. Prevalencia de Retinopatía diabética en una población diabética registrada en atención primaria. 2017.

2. Maclennan P, McGwin G, Heckemeyer C, et al. Eye care use among a high-risk diabetic population seen in a public hospital's clinics. JAMA Ophthalmology. 2014;132(2):162-167.

3. Cook S. Diabetic retinopathy - the Ophthalmology Society of Southern Africa screening programme. South African Medical Journal SuidAfrikaanse TydskrifVir Geneeskunde. 2013;103(7):449-451.

4. Moctezuma Y, Rodríguez L, Parra J. Asociación de albúmina sérica con severidad de retinopatía diabética. Medicina Interna De Mexico. 2012;28(3):213-219. 
5. Sigler A. Análisis de algunas variables clínicas en relación con la retinopatía diabética. Rev Cubana Oftalmol.1996;9(2).

6. Ramasamy K, Raman R, Tandon M. Current state of care for diabetic retinopathy in India. Current Diabetes Reports. 2013;13(4):460-468.

7. Mijail T, Martínez Oslay, Rivas MC, et al. Factores de riesgo en el desarrollo de la retinopatía diabética. Rev Cubana Oftalmol. 2011;24(1):86-99.

8. Cuba. Ministerio de Salud Pública. Dirección Nacional de Registros Médicos y Estadística de Salud. Anuario Estadístico de Salud 2010. La Habana: MINSAP. 2011. p. 1-174.

9. Carolino IDR, Molena-Fernándes CA, Tasca RS, et al. Risk Factores de riesgo en pacientes con diabetes mellitus tipo 2. Rev Latino-am Enfermagem. 2008;16(2):238-44.

10. Pérez M, Triana I, Pérez L, et al. Caracterización clínica de la retinopatía diabética en diabéticos tipo 2 atendidos en el Servicio de Retina del Centro Oftalmológico "Dr. Salvador Allende" de la Habana. Mediciego. 2012;18(1):47-53.

11. Carolino IDR, Molena-Fernándes CA, Tasca RS, et al. Risk Factores de riesgo en pacientes con diabetes mellitus tipo 2. Rev Latino-am Enfermagem. 2008;16(2):238-44.

12. Llerena AY, PérezAE. Principales afecciones oftalmológicas en el municipio de Guanes, Pinar del Río. Rev Cubana Oftalmol. 2010;23(1):122-135.

13. Mesa JA, Faget O, Hernández Yero A. Características clínicas de los pacientes enfermos con diabetes mellitus ingresados en el centro diurno del INEN. Rev Cubana Endocrinol. 2001;12 (Supl 48).
14. Cardona D, Duconger R, Soto G. Prevalencia de retinopatía diabética en el distrito 4 del municipio de Santiago de Cuba. Año 2000. Rev Cubana Endocrinol. 2001;12:(Supl 26).

15. Crespo Valdés Nelson, Padilla González José de la C, González Fernández Rebeca, et al. Prevalencia de la retinopatía diabética en pacientes del nivel primario de salud. Rev Cubana Med Gen Integr. 2004;20( 2 ).

16. Romero-Aroca $\mathrm{P}$, Fernández-Alart $\mathrm{J}$, Baget-Bernaldiz $\mathrm{M}$, et al Epidemiología de la retinopatía diabética en pacientes tipo II: Cambios observados en una población entre los años 1993 y 2005, tras los nuevos criterios diagnósticos y un mayor control de los pacientes. Arch Soc Esp Oftalmol. 2007;82(4):209-218

17. Perera Miniet Elianne, Ramos López Meisy, Padilla González Carmen María, et al. Comportamiento clínico-epidemiológico de la retinopatía diabética en el municipio Marianao de agosto - noviembre 2007. Rev Cubana Oftalmol. 2011;24(2):287-298.

18. Licea Puig Manuel E, Cruz Hernández Jeddú, Domínguez Alonso Enma et al. Frecuencia de retinopatía diabética y su relación con algunas variables clínicas y bioquímicas asociadas a la diabetes tipo 1. Rev Cubana Endocrinol. 2006;17(3).

19. Osorio Illas Lisis, Paisán Rizo Wendy Miguel, HitchmanBarada Dora L. Risk factors associated with diabetic retinopathy in type II diabetic patients. Rev Cubana Med Gen Integr. 2006;22(1).

20. Sánchez M, Díaz-Llopis M, Benítez JM, et al. Manifestaciones Oftalmológicas de las Enfermedades Generales. LXXVII Ponencia Oficial de la Sociedad Española de Oftalmología. 2001;IX.1:261-81. 